\title{
Exotismo e autenticidade: relatos de viajantes à procura de sexo*
}

\author{
Adriana Piscitelli**
}

\begin{abstract}
Resumo
A produção sócio-antropológica que trata do turismo discute a oposição entre o caráter de massa atribuído ao olhar dos turistas contemporâneos e o caráter individual vinculado à "viagem". Este texto dialoga com argumentos presentes nessa oposição, a partir da análise etnográfica de relatos de viajantes à procura de sexo que freqüentam pontos do circuito internacional de turismo sexual. Centrando-se em narrativas ficcionais/experienciais, Plateforme, romance de Michel Houellebecq, recentemente publicado, os relatos de viagem de Mattioli Ross e histórias contadas por viajantes à procura de sexo, no marco de uma pesquisa sobre turismo sexual internacional no Nordeste do Brasil, o texto estabelece esse diálogo considerando as noções centrais presentes nesse conjunto de relatos atravessados por gênero: exotismo, sexualidade e autenticidade.
\end{abstract}

Palavras-chave: Turismo, Sexualidade, Prostituição.

\footnotetext{
* Recebido para publicação em agosto de 2002. Este texto está vinculado à pesquisa "Entre a prostituição e os namoros de verão. Gênero e sexualidade no contexto do turismo internacional, em Fortaleza", apoiada pela FAPESP. Agradeço a Miriam Pillar Grossi, Marília Carvalho, Maria Filomena Gregori, Mariza Corrêa, Ana Maria Medeiros da Fonseca e aos participantes do Fórum de Pesquisa Etnografia dos Relatos de Viagem da $23^{a}$ Reunião Brasileira de Antropologia (Gramado, 2002) os comentários e observações realizadas.

*** Pesquisadora do Núcleo de Estudos de Gênero - Pagu da Universidade Estadual de Campinas.pisci@uol.com.br.
} 
Exotismo e autenticidade

Exoticism and Authenticity:

Tales of Travelers in Search of Sex

\begin{abstract}
The socio-anthropological production on tourism opposes the mass character imputed to the views of contemporary tourists to the individual character attributed to the "trip". This text establishes a dialogue with arguments present in that opposition, based on ethnographic analyses of tales by travelers in search of sex used to places in the international circuit of sexual tourism. Centering on fictional/experiential accounts, Plateforme, recently published novel by Michel Houellebecq, Mattioli Ross' travel accounts and tales told by travelers in search of sex, framed by a research on international sexual tourism in Brazil's Northeast, the text establishes such a dialogue considering the notions central to those accounts crisscrossed by gender: exoticism, sexuality, authenticity.
\end{abstract}

Key Words: Tourism, Sexuality, Prostitution. 
Adriana Piscitelli

As pessoas que estabelecem para si mesmas um esquema para viajar, geralmente o fazem pensando alcançar um ou mais dos seguintes objetivos. Primeiro, reunir uma coleção curiosa, como os filósofos naturalistas, os virtuosos, ou os antiquários. Segundo, aprimorar-se no que se refere à pintura, escultura, arquitetura e música. Terceiro, obter a reputação de serem homens de virtudes e de gostos elegantes. Quarto, adquirir ares estrangeiros, e ornar seus seres queridos com roupas elegantes e novas modas, e suas conversações com novas frases. Ou, quinto, apagar preconceitos locais (o qual é, certamente, o motivo mais

louvável, embora não seja o prevalecente) e para adquirir uma visão mais ampla e imparcial dos homens e das coisas, o que nenhum único país pode possibilitar Josiah Tucker, Instructions for Travellers, $1757^{1}$

A viagem é fatal para o preconceito, a intolerância e a estreiteza mental Mark Twain, The innocents abroad, $1869^{2}$

Não somos turistas, somos viajantes... o turista pensa em voltar para casa assim que chega...

E o viajante pode não voltar nunca mais. Diálogo inicial do filme Sob o Céu que nos Protege, de Bernardo Bertolucci. ${ }^{3}$

\footnotetext{
${ }^{1}$ Citado em Chambers, Erve. Native Tours, the anthropology of travel and Tourism. Waveland Press, Illinois, 2000 (tradução minha).

2 Citado em RAPPORT, Nigel e Overing, Joana. Social and Cultural Anthropology, the Key Concepts. London and New York, 2000, (tradução minha).

3 Esse diálogo tem lugar quando um grupo, integrado por dois homens e uma mulher de Nova York, desembarca em algum lugar do Norte da África. Situado após a Guerra, o filme, que mostra imagens em branco e preto de arranha-céus, trânsito intenso, trabalhadores esgotados viajando em trens suburbanos, pessoas tirando comidas de máquinas, vai adquirindo cores na medida em que o grupo se aproxima da terra. Iniciando o diálogo, a mulher procura na bagagem um chapéu de explorador.
} 
Exotismo e autenticidade

\section{Apresentação}

A produção sócio-antropológica sobre turismo traça uma marcada distinção entre "viagem" e turismo. Nessa diferenciação, a percepção da diferença que resulta da viagem tende a ser valorizada positivamente e a experiência turística é, muitas vezes, inferiorizada. A valorização da viagem, porém, está longe de limitar-se aos escritos acadêmicos - $e$ as epígrafes que introduzem este trabalho, textos que fazem parte da literatura dos séculos XVIII, XIX e do cinema contemporâneo, mostram a extensão dessas idéias. Precisamente, a recorrente presença de noções do "saber comum" na produção acadêmica sobre turismo conduz Malcolm Crick, um dos autores mais citados nesses trabalhos, a indagar-se sobre $\mathrm{o}$ grau no qual as imagens culturais (emocionalmente carregadas) em relação às viagens e aos turistas são incorporadas na produção das ciências sociais sobre o tema. ${ }^{4}$

Segundo esse autor, a literatura sobre viagens do século XIX retrata a viagem como experiência restrita e valorizada. ${ }^{5}$ Ao contrário, os relatos do século XX descrevem o turismo de massa à maneira de uma "descendência degenerada" da viagem. De acordo com Crick, essa inferiorização se reitera em parte da

4 CRICK, Malcolm. Representations of international tourism in the social sciences: Sun, sex, sights, savings and servility. Annual Review of Anthropology 18, 1989, pp.307-344.

${ }^{5}$ Clifford converge com Crick no que se refere a sublinhar o caráter restrito outorgado a essa experiência na literatura de viagem, chamando a atenção para as exclusões presentes na noção de viagem, uma noção que estaria marcada por diferenciações de classe, gênero, raça, localizações culturais e históricas e privilégios. Segundo Clifford, essa literatura não vincula as mulheres à idéia de verdadeira viagem (elas viajam como acompanhantes, ou são consideradas exceções). Criados e criadas, guias, pessoas não brancas, conformam categorias de pessoas ignoradas, também, por essa noção, uma vez que, contando com um status inferior ao do independente viajante burguês, branco, essas pessoas estão distantes de serem vinculadas às imagens de exploradores heróicos, intérpretes estéticos ou autoridades científicas. CLIFFORD, James. Routes. Travel and translation in the late twentieth century. Cambridge, Harvard University Press, 1997, pp.32-33. 
produção acadêmica, na qual se assinala a conexão etimológica do termo viajar (travelling) com a noção de trabalho (travail), enquanto no turismo reina a passividade e não a atividade. Carecendo de sofisticação ou da possibilidade de proporcionar insights, o turismo seria a apoteose do "pseudo", no sentido em que o turista teria uma grande disponibilidade para aceitar a superficialidade e ainda preferiria experiências falsas às genuínas: os turistas não apenas aceitariam o banal, o estimulariam. ${ }^{6}$

Se a distinção entre "viagem" e turismo é extremamente difundida, nos trabalhos sócio-antropológicos essa diferença adquire conotações particulares. $\mathrm{Na}$ oposição entre o caráter individual vinculado à viagem e o caráter de massa atribuído ao olhar dos turistas contemporâneos, o turismo tende a ser caracterizado através de discussões sobre a idéia de autenticidade. Esse debate acirra-se, particularmente, nas leituras centradas no turismo considerado pós-moderno, isto é, o turismo vinculado à sociedade pós-industrial. Tomando como referência um estilo de viagem que é inserido nesse tipo de turismo, o turismo sexual, neste trabalho dialogo com os argumentos apresentados nessas discussões, a partir da análise de relatos de viajantes à procura de sexo que freqüentam pontos do circuito internacional de turismo sexual.

Centrando-me em narrativas ficcionais/experienciais, Plateforme, romance de Michel Houellebecq ${ }^{7}$ e o relato de viagem de Mattioli Ross ${ }^{8}$ e tomando como referência histórias contadas por viajantes à procura de sexo, no marco de uma pesquisa sobre

${ }^{6}$ Boorstin, D. The Image. A Guide to Pseudo-Events in America. New York, Atheneum, 1972, citado em CRICK, M. Representations of international tourism... Op. cit., p.308.

7 HouellebeCQ, Michel. Plateforme. Paris, Flammarion, 2001.

8 Mattioli Ross, Cláudio. Vivendo volando, um uomo, fli affari, le donne, il sesso. Bologna, Gianni Monduzzi Editore, 1998. 
Exotismo e autenticidade

turismo sexual internacional no Nordeste do Brasil ${ }^{9}$, estabeleço esse diálogo considerando as noções centrais presentes nesse conjunto de relatos. Trata-se de materiais diferenciados no que se refere às suas condições de produção. Essa heterogeneidade amplia-se levando em consideração as nacionalidades dos narradores - francês, italiano, inglês, estadounidenses. No entanto, embora leve em conta os aspectos específicos desses textos, analiso esses relatos considerando que eles permitem pensar em configurações de valores associados, num determinado período, a certos âmbitos da vida social. ${ }^{10}$

Inserindo-me na discussão sobre a diferenciação entre viagem $e$ turismo $e$ prestando atenção às idéias presentes nos relatos desses viajantes à procura de sexo, argumento que as discussões sobre autenticidade, presentes na produção sócioantropológica sobre turismo, apresentam aspectos frágeis para sustentar essa oposição. E vale mencionar que essa noção é central no procedimento através do qual os narradores considerados ancoram a singularidade de suas experiências na condição de "viajantes", distanciando-se por meio dela, dos (outros) turistas.

Apresento, em primeiro lugar, os argumentos tecidos em torno da noção de autenticidade na discussão sócio-antropológica sobre turismo. Mostro, depois, as idéias centrais presentes nos relatos dos viajantes à procura de sexo, prestando atenção à textualidade dessas narrativas (isto é, à maneira como os

9 Piscitelli, Adriana. Entre a prostituição e os namoros de verão. Gênero e sexualidade no contexto do turismo internacional, em Fortaleza. Relatório parcial de pesquisa apresentado à Fapesp, 2001.

${ }^{10}$ Falo em configurações, no sentido de referir-me não a um traço isolado mas a idéias que mantêm entre si certas relações. Assim, concordo com a idéia de Dumont de que embora as configurações variem de um texto a outro, de um autor a outro, não variam completamente e apresentam, em cada nível de generalização, aspectos em comum. DuMONT, Louis. $O$ individualismo. Uma perspectiva antropológica da ideologia moderna. Rio de Janeiro, Rocco, 1983, p.23. 
argumentos são estruturados $e$ apresentados $e$ ao que é dito). Nessas histórias, a noção de autenticidade mantém relações com idéias específicas sobre exotismo e sexualidade que adquirem sentido no marco da construção de desigualdades atravessadas por distinções de gênero e raça. Concluindo, faço alguns comentários sobre como o uso dessa noção se relaciona com as idéias presentes na literatura acadêmica sobre turismo.

\section{"Viagem", turismos...}

A viagem impossível é essa viagem que já não faremos mais. Essa viagem que poderia ter nos feito descobrir novas paisagens $e$ novos homens, que haveria podido nos abrir o espaço de novos encontros. Isso aconteceu alguma vez e alguns europeus sem dúvida experimentaram fugidiamente o que nós experimentaríamos hoje se um sinal indiscutível provasse a existência, em alguma parte do espaço, de seres vivos capazes de comunicar-se conosco... E nós, o que fizemos de nossas viagens e de nossos descobrimentos?...

...viajar, sim, é preciso viajar, seria necessário viajar, mas, sobretudo, não fazer turismo. Marc Augé: El viaje imposible ${ }^{11}$

Entre os autores que participam na discussão sócioantropológica sobre turismo há um acordo em assinalar que o século $\mathrm{XX}$ é palco de uma explosão nos números dos que "viajam", que se intensifica particularmente no período após a "Segunda Guerra Ocidental". Um conjunto de fatores, entre os quais se conta a expansão de meios de transporte rápidos $e$ econômicos, das companhias de viagem e da informação televisada sobre outras partes do mundo e a crescente disponibilidade de recursos econômicos suplementares para gastar

${ }^{11}$ AugÉ, Marc El viaje imposible. El turismo y sus imágenes. Barcelona, Gedisa, 1998, pp.15-16. 
Exotismo e autenticidade

em lazer, teria dado lugar ao surgimento do "turista" ${ }^{12}$, uma nova categoria de expectativas e experiências sociais. ${ }^{13}$

Esse acordo se interrompe quando se trata de caracterizar o turismo massificado, decorrente do processo acima mencionado. Algumas abordagens caracterizam o turismo de massa como marcado pela falta de autenticidade, considerando-o uma forma de experiência organizada para evitar o contato real com o outro, uma forma de ser trivial, manufaturada, uma forma de viagem maculada, tornada segura através da comercialização. Numa leitura na qual a viagem (individual) é percebida como caracterizada por traços que a vinculam a experiências heróicas, educacionais, científicas, de aventuras ${ }^{14}$, e valorizada em relação ao turismo, a viagem, neste sentido, já não existe. A viagem da Idade do Descobrimento, dos exploradores, teria passado há muito tempo. Na Idade Industrial, as Grand Tours aristocráticas do século XVIII teriam dado lugar à possibilidade das viagens para a classe média. Mas, esse mundo também teria morrido, invadido pelo turismo de massa na idade pós-industrial. Segundo Boorstin, o autor que desenvolveu de maneira mais incisiva essas idéias, nesse tipo de turismo, o prazer está vinculado às atrações "inventadas"; o gozo, à credulidade em "pseudo-acontecimentos". Ao longo do tempo, através de anúncios e da mídia, as imagens geradas pelos diferentes olhares do turista teriam passado a

\footnotetext{
${ }^{12}$ RAPPORT, N. e OVERING, J. Social and Cultural Anthropology... Op. cit., p.354.

${ }^{13} \mathrm{O}$ caráter da experiência social é relevante nas definições antropológicas do turista, "uma pessoa desfrutando temporariamente de lazer que voluntariamente visita um lugar distante de casa com o propósito de experimentar uma mudança"; "um viajante temporário que procura prazer a partir das novidades e da mudança experienciadas numa viagem relativamente longa e não recorrente". SMITH, Valene. Hosts and Guests. Blackwell, 1989, grifado meu; COHEN, Erik. Who is a tourist?: A conceptual clarification. The Sociological Review, vol 22, $\mathrm{n}^{\circ} 4$, November 1974, p.533

${ }^{14}$ Nos termos de Clifford, essas experiências poderiam ser consideradas "enobrecedoras". ClifFORD, J. Routes. Travel and translation... Op. cit., p.31.
} 
constituir um sistema de ilusões, fechado, que se auto-perpetua. ${ }^{15}$ As explorações descobriam o ainda não descoberto. As "viagens" pretendiam revelar o que a história tinha descoberto. Mas, o turismo estaria intimamente ligado a um mundo descoberto (e até criado) por empresários e lançado ao mercado na forma de pacotes. ${ }^{16}$

Essa visão da passagem do "viajante individual" ao "turista de sociedade de massa", marcada pela (in)autenticidade da experiência, é uma das interpretações correntes nas discussões sócio-antropológicas sobre turismo. E vale registrar que esse caráter de falta de autenticidade é assinalado de maneira dramática quando se trata do turismo organizado nos países Ocidentais e voltado para as nações do Terceiro Mundo. Brunner afirma que o turismo tem menos a ver com o que os outros realmente são do que com a maneira como eles são imaginados $e$, nesse sentido, o turismo é análogo a qualquer outra forma de representação. Fazendo uma lista de tours contemporâneos turismo de exploração, "commando", colonial, sexual -, o autor chega à conclusão de que essas viagens têm suas raízes na consciência capitalista Ocidental. ${ }^{17}$ Seriam tours do desejo, dizendo mais da sociedade que os organiza que das sociedades visitadas, tours nos quais o Terceiro Mundo se torna um playground para o imaginário Ocidental, nos quais aqueles que controlam recursos obtêm um espaço discursivo para "atuar" suas fantasias. ${ }^{18}$

\footnotetext{
${ }^{15}$ BOORSTIN apud URRY, John. O olhar do turista. Lazer e viagens nas sociedades contemporâneas. São Paulo, Sesc/Studio Nobel, 1996 [1990], p.23.

${ }^{16}$ Fussel, P. Abroad. British Literary travelling Between the Wars. New York, Oxford University Press, 1980, citado em CRICK, M. Representations of international tourism... Op. cit., p.308.

${ }^{17} \mathrm{O}$ Turismo de Exploração reproduziria as explorações da Era dos Descobrimentos, o "commando", nos EEUU, instrução militar para agir na guerra de guerrilhas. BRUNNER, Edward. OF cannibals, tourists and ethnographers. Cultural Anthropology, vol 4, n 4, 1989, p.440.

${ }^{18}$ ID., IB.
} 
Exotismo e autenticidade

Algumas perspectivas, porém, contestam tanto a distinção entre "viagem" e turismo como o caráter de não autenticidade atribuído a este último. Reconhecendo que o turismo moderno é um fenômeno recente e diferenciado, em diversos sentidos, de tradições de viagem anteriores, Chambers discute a distinção entre os dois termos (viagem/turismo), que está ancorada na "qualidade" das experiências da viagem. ${ }^{19} \mathrm{E}$ ao discutir essa qualidade, alinha-se com autores que afirmam a autenticidade da experiência turística.

Baseando-se na premissa de que a vida era mais real antes da emergência do capitalismo industrial, MacCannell, um dos autores de maior peso nessa linha de pensamento, afirma que a viagem do turista é uma espécie de vôo nostálgico para afastar-se das implicações da vida moderna. No passado, a base da autenticidade teria sido a conexão que as pessoas sentiam com seus meios sociais - a falta de contradições entre trabalho, família e comunidade. $\mathrm{Na}$ análise desse autor, a modernidade produz sentimentos de alienação e falta de autenticidade. Mas, produz, também, o desejo de escapar procurando algo que é real. O turista buscaria um tipo de transcendência da influência da vida moderna, não distante de uma experiência religiosa. Todo turista personificaria a busca da autenticidade - e essa busca seria uma versão moderna da preocupação universal com o sagrado. A idéia de MacCannell não é argumentar que as performances realizadas para turistas sejam autênticas, mas que o objetivo do turista é procurar, por trás dos bastidores, algo real para experienciar. Assim, no trabalho desse autor a noção de autenticidade está vinculada, sobretudo, à "motivação" do turista. ${ }^{20}$

\footnotetext{
${ }^{19}$ A conceitualização do turismo realizada por esse autor é condizente com essa reflexão. Ele caracteriza o turismo como qualquer tipo de atividade de viagem que inclua a experiência auto-consciente de outro lugar. CHAMBERS, E. Native Tours... Op. cit., p.xi.

${ }^{20}$ MaCCANnEl, Dean. The tourist, a new theory of the leisure class. New York, Shocken, 1989.
} 
Essa polaridade na percepção da autenticidade é interrompida por outras abordagens. Erik Cohen considera que o problema presente nas reflexões de Boorstin e MacCannell é que ambos consideram o turista como se se tratasse de um papel unitário, quando as evidências empíricas mostram que os turistas diferem consideravelmente no que se refere a suas motivações, estilos de viajar $e$ atividades. ${ }^{21}$ Certos tipos de turistas estariam refletidos nas idéias de um ou outro autor, mas existiriam outros tipos e essa existência possibilitaria dissolver a polaridade autenticidade/não autenticidade. Desenvolvendo uma classificação baseada nos modos de experiência turística ${ }^{22}$, Cohen afirma que, embora certos tipos de turistas procurem apenas prazer, há outros centrados na busca de significado e autenticidade - isso não significa, porém, que os viajantes obtenham respostas adequadas às suas expectativas. Essas respostas seriam obtidas mais facilmente quando se trata de viajantes à procura de diversão ou recriação - e uma vez que esses tipos de viajantes não procuram autenticidade, suas experiências não poderiam ser falsas. A situação diferiria quando se trata de turistas para os quais a autenticidade da experiência é crucial para seu significado.

\footnotetext{
${ }^{21}$ COHEN, Erik. The sociology of tourism, approaches, issues and findings, Annual Review of sociology 10, 1984, p.378.

${ }^{22}$ Esses modos são classificados como: Recreacional - a viagem é, apenas, mais uma forma de entretenimento, tal como o cinema ou o teatro, que proporciona descanso e bem-estar -, diversionária - simples escapatória da rotina -, experiencial - procura o significado perdido na sua sociedade buscando-o em "outras" sociedades -, experimental - vinculado aos turistas considerados pósmodernos, que, na sua procura por significado, experimentam modos de vida alternativos, viagens, drogas e misticismo seriam caminhos nessa busca $e$ existencial - são aqueles que procuram um novo centro espiritual em outras culturas, e que tentam obtê-lo submetendo-se a elas. COHEN, Erik. A phenomenology of tourist experiences. Sociology, vol 13, n² 2, May 1979, p.183.
} 
Exotismo e autenticidade

Não pretendo esgotar aqui os argumentos elaborados nessa discussão. ${ }^{23}$ Interessa-me apenas assinalar que esse debate mostra um problema central. As abordagens apresentadas caracterizam o turismo através de uma discussão em torno da noção de autenticidade na qual se misturam diferentes planos de análise. Além disso, cabe perguntar-se sobre a validade da maneira como é conceitualizada a "autenticidade".

Algumas versões vinculam a falta de autenticidade da experiência turística à estrutura da indústria turística, aos tipos de "mundos" por ela criados. Outras perspectivas defendem a autenticidade da experiência turística, mas o fazem ancoradas nas motivações dos turistas, particularmente de alguns tipos específicos de turistas. Mas, há um "gap" entre umas e outras abordagens. Quero dizer que as motivações dos turistas apresentam uma certa autonomia em relação à alegada falta de autenticidade dos "mundos" turísticos. A passagem, sem mediações, de um a outro plano torna essa discussão problemática. Mas, não se trata apenas disso. A idéia geral de falta de autenticidade nos "mundos" turísticos apresenta problemas em si mesma. Parece-me que ela está apoiada num procedimento que confunde uma noção particular de tradição com autenticidade. Digo particular porque a noção de tradição operacionalizada remete a uma idéia de cultura fechada às influências externas e a

\footnotetext{
${ }^{23}$ Vale mencionar que Urry, levando seriamente em conta uns e outros argumentos, chega à conclusão de que parece incorreto sugerir que a busca de autenticidade está na base da organização do turismo. Segundo esse autor, pode ser que a procura daquilo que consideramos ser os elementos autênticos constitua um componente importante, mas isso se dá apenas porque existe um contraste com as experiências cotidianas. Essa diferença, entre o lugar normal de residência/trabalho e o objeto de olhar do turista, constituiria, sim, uma característica principal da organização do turismo. Isso sem contar, segundo o autor, que alguns visitantes, considerados "pós-turistas", se deliciam com a falta de autenticidade da experiência turística normal. Eles encontrariam prazer na multiplicidade dos jogos turísticos. Saberiam que a experiência turística não existe, não passa de jogos ou textos, que podem ser exercitados ou interpretados. URRY, J. O olhar do turista... Op. cit., pp.27-28
} 
um certo congelamento. E ao fazê-lo ignora a participação das vozes e realidades locais na construção desses mundos turísticos e o efeito deles nos processos culturais locais.

Nos termos de Crick, com os quais concordo, essa visão supõe a existência de uma autenticidade cultural à qual esses mundos construídos externamente (por meio da indústria turística) impediriam $O$ acesso. $O$ autor chama a atenção para a importância de perguntar-se sobre o que é autêntico numa cultura. Afinal, todas as culturas estão num processo de construção e representação (staging) permanente e, nesse sentido gral, toda cultura é uma "autenticidade representada" (no sentido de atuada à maneira de um teatro/staged) ${ }^{24}$ Considerando a mudança como um estado permanente, perceber a representação/atuação vinculada ao turismo como algo distante da autenticidade careceria de sentido. $\mathrm{E}$, eu adicionaria, também carece de sentido ignorar o entrelaçamento dos mundos turísticos contemporâneos com os processos culturais locais, considerando autêntico tudo aquilo anterior e exterior a este tipo particular de "contato".

A fragilidade dessa discussão (e de sua adequação para ancorar a distinção entre viagem $e$ turismo) torna-se particularmente evidente na análise dos relatos de viajantes à procura de sexo. Seres que personificam um dos "tipos" de turismo contemporâneo vinculado às expressões mais agudas de falta de autenticidade justificam o objetivo sexual de suas viagens, precisamente, através da incessante procura do "verdadeiro". Antes de proceder a essa análise, porém, é necessário apresentar os narradores, considerando as condições de produção dos relatos.

${ }^{24}$ CRICK, M. Representations of international tourism... Op. cit., p.336. 
Exotismo e autenticidade

\section{Narradores: viajantes à procura de sexo}

Plateforme, um dos textos aqui analisados, provocou, no ano passado, intensa curiosidade e um escândalo público na França $^{25}$, vinculado às idéias de que o livro defende o turismo sexual e é profundamente racista $e$ às vívidas descrições que o autor, Michel Houellebecq faz desse tipo de turismo. O romance foi escrito em Pattaya, resort destinado ao turismo sexual, na Tailândia, próximo a Bancoc, onde o autor esteve em contato com prostitutas $e$ visitou os salóes de massagem que lhe serviram de inspiração. No livro, Houellebecq mistura ficção e realidade. Nouvelles Frontiéres, a agência de viagens nomeada em Plateforme, é "real"26 - o autor viajou a Tailândia utilizando os serviços dessa agência. O caráter ficcional/experiencial do livro aparece sintetizado no nome outorgado ao personagem principal, Michel, que replica o nome do autor.

Michel-personagem é um apático funcionário do Ministério de Cultura da França, de 40 anos, cuja mediocridade se expressa na corporalidade - costas estreitas, nem alto, nem baixo, nem magro, nem gordo, nem atraente, nem repulsivo, com uma cabeleira que já começou a ralear e, no entanto, ainda não desapareceu. Solteiro, arredio aos relacionamentos amorosos, o narrador reflete com crueza e com um certo cinismo sobre as condições da morte do pai e, sobretudo, acerca de sua própria solidão,

Lamento um pouco o celibato na minha vida. É desagradável, sobretudo, nas férias. As pessoas desconfiam dos homens que passam as férias sós, a partir de uma certa

\footnotetext{
${ }^{25}$ Segundo nota da Folha de S.Paulo teria vendido 200.000 cópias em duas semanas. Polêmica. Protagonista considera uma situação ideal de troca a satisfação do turista com prostitutas do terceiro mundo. Romance francês defende turismo sexual. Folha de S.Paulo, 17/09/2001.

${ }^{26}$ ID., IB.
} 
idade: supõem que se trata de bastante egoísmo e, sem dúvida, de um pouco de vício. ${ }^{27}$

O narrador considera-se um medíocre. A cor que tinge sua vida é o cinza: é o tom escolhido para suas roupas e é o principal matiz do seu cotidiano, uma rotina que, para além de um trabalho desinteressante, inclui monótonas visitas vespertinas a sessões de peep-shows nas quais se masturba, e horas de zapping até a madrugada frente aos mais de cem canais de sua TV. Altamente reflexivo, Michel medita sobre os atributos de seu caráter, entre os quais não se conta a bondade. Percebe-se, sobretudo, como indiferente e incapaz de qualquer sentimento de solidariedade. $\mathrm{O}$ narrador estabelece relações entre a falta de paixão que permeia sua existência e a vida sem preocupações que lhe oferece seu país, mediante a estabilidade do clima político, a estrita legislação que garante o patrimônio, poderosos apoios estatais ao sistema bancário. Esse país que lhe garante um emprego tranqüilo e um salário correto é percebido como sinistro, devido a seu caráter inteiramente administrativo, e distante da idéia de libertinagem à qual é às vezes associado. ${ }^{28}$

A herança que, após o assassinato do pai, receberá o narrador, estimula ações que modificam sua vida. Passa o último dia do "luto" remunerado concedido pelo serviço público francês escolhendo roteiros de viagem. O narrador se reconhece nos "desejos de liberdade" que atribui aos habitantes da Europa Ocidental. Do mesmo modo que eles, precipita-se ao outro lado do mundo como se fosse um "evadido de uma prisão". ${ }^{29}$ Seu maior desejo, análogo ao que atribui aos outros europeus "médios", é "viajar". Do ponto de vista de Michel, viajar é consumir: ele reflete sobre os circuitos a serem escolhidos considerando, simultaneamente, as diferentes perspectivas teóricas

\footnotetext{
${ }^{27}$ HouellebeCQ, M. Plateforme. Op. cit., p.12.

${ }^{28}$ ID., IB., p. 70.

${ }^{29}$ ID., IB., p.34.
} 
Exotismo e autenticidade

que tratam do consumo, coincidindo com a de Marshall, segundo a qual o comprador é um indivíduo racional que procura maximizar sua satisfação levando em conta os preços. ${ }^{30} \mathrm{E}$ o sexo a ser obtido durante a viagem integra-se na mesma lógica.

Optando por "Tropic Thai", um pacote classificado sob o rótulo de "circuito de aventuras", o narrador, que se distancia dos/as companheiros/as de viagem de diversas maneiras, dedicase ao consumo das prostitutas locais. As relações com elas mantidas viabilizam suas reflexões sobre a alteridade acessando, ao mesmo tempo, suas capacidades de conexão (consigo mesmo e com os outros). Parte do efeito desse processo é, no regresso das férias, o estabelecimento de uma relação afetiva. A namorada é uma garota francesa que fez parte do grupo, alta executiva de uma agência de viagens, cujas características de temperamento, consideradas por Michel como pouco usuais numa européia, o incitam a pensar numa união estável $e$, inclusive, em reprodução.

Michel acompanha a namorada em algumas viagens - entre elas a Cuba -, compartilhando com ela aventuras eróticas, e utiliza seu "saber" experiencial sobre as viagens com objetivos sexuais, contribuindo na elaboração de um projeto para a agência na qual a namorada trabalha: tours sexuais para europeus, no Terceiro Mundo. Após uma experiência inicial na Tailândia, os tours se expandiriam em outros países da Ásia, na África e na América Latina, incluindo o Brasil. A primeira viagem, que é um enorme sucesso de vendas, é o nó em torno do qual se alinhava o desfecho trágico da história - o grupo é atacado por fundamentalistas muçulmanos que, pouco compreensivos com as atividades dos europeus, assassinam boa parte dos integrantes, entre eles, a namorada francesa de Michel. Assim que se repõe minimamente, Michel, emocionalmente anestesiado, retorna à Tailândia e, após alugar um quarto em Pattaya, começa a escrever um livro sobre suas experiências.

${ }^{30}$ ID., IB., p. 22. 
Vivendo Volando, um uomo, gli affari, le donne, il sesso... é um texto que se apresenta como inteiramente experiencial. A contracapa esclarece que o livro não é um guia turístico, nem um diário erótico - embora alguns trechos possam ter um certo apelo erótico. Tratar-se-ia de "uma galeria de retratos de mulheres, com o fundo de lugares famosos, de Bancoc a Hong Kong, de Cuba a Rio". ${ }^{31}$

Cláudio Mattioli Ross, o autor, apresenta-se como um empresário do norte da Itália que, completando cinqüenta anos, escreve um relato de suas viagens, majoritariamente de negócios, através do mundo. O livro é construído como se tivesse sido redigido em viagem - o final de cada capítulo tem a indicação de um vôo - Lahore-Hong Kong -, um aeroporto - Heathrow -, uma cidade "distante" - Hong Kong, Kunmig - uma data, algum mês do ano 1997. Os episódios, longe de estarem organizados cronologicamente, parecem seguir o fluxo da memória - o primeiro remete à primeira metade da década de 1980, os seguintes referem-se aos anos 70, os que seguem, aos anos 90 , voltando depois aos 80 , finalizando na segunda metade da década de 1990. No marco de salas de espera, descritas como verdadeiros "não-lugares", do Clube Executivo da British Airways, e imerso num meio de "semelhantes" - outros executivos viajando, sós, pelo mundo - o autor apresenta as lembranças como elemento que, singularizando-o, concedem uma certa unidade às suas experiências.

A narrativa, porém, e esse é o ponto distintivo de livro, é alinhavada através dos relacionamentos sexuais que Mattioli Ross mantém, a partir dos 20 anos, com mulheres de diversas idades e cores em países diferentes: jovens trabalhadoras do Sul de Europa, mulheres de diversas camadas sociais de nações distantes e pobres e, também, italianas. Nos lugares exóticos (e lugar/posto)

${ }^{31}$ Essa apresentação também esclarece que embora o livro revele um certo machismo, a sensibilidade "quase feminina" do autor deve tornar a leitura agradável ainda para as mulheres. MATTIOLI Ross, C. Vivendo volando... Op. cit., capa do livro. 
Exotismo e autenticidade

é um termo recorrente para referir-se a eles no texto, trata-se, a maior parte das vezes, de prostitutas. Referindo-se à primeira experiência desse tipo, ocorrida, em 1970, na Jamaica, o autor afirma: "Naquela viagem me decidi pela minha primeira puta porque, saltando de um lugar a outro, não podia ter todo o tempo que desejava para encontrar uma garota". ${ }^{32}$ O livro, significativamente, inicia-se com o relato de uma visita a um (elegante) bordel de Acapulco. ${ }^{33}$

Nessa trama, detalhes biográficos esparsos informam sobre a vida do autor, o relacionamento com os pais, com outros empresários (amizades que parecem ser seladas mediante viagens com objetivos sexuais), sobre as namoradas conterrâneas, com as quais mantêm relacionamentos sexuais marcados por permanentes (e monótonas) negociações de poder. Filho de um funcionário bancário, o narrador estudou em Lucca. Abandonou a formação universitária, optando por um emprego arranjado pelo pai numa firma de importações, cujas atividades o levaram a atravessar o mundo. Perpassado por um certo cinismo no que se refere à sua geração - de todas as novidades do distante 68, ele afirma, apenas a "liberação sexual" parecia ter sobrevivido, ou pelo menos era o único aspecto que ainda era possível aproveitar $^{34}$ - Mattioli Ross incorpora, no livro, episódios (sexuais) que tiveram lugar em férias e na cidade de residência, na Itália. Vivendo Volando trata, basicamente, do aspecto sexual das viagens de negócios, nos momentos e dias de lazer que delas fazem parte. E vários dos "postos" nos quais elas têm lugar, coincidem com cidades integradas no circuito internacional de turismo sexual: Ocho Rios (Jamaica), Varadero, Pattaya, Bancoc, Hong Kong...

Steve, um musculoso cabeleireiro inglês de 32 anos, visitou o Brasil pela primeira vez em janeiro de 2000. Na época, esse

\footnotetext{
${ }^{32}$ Mattioli Ross, C. Vivendo volando... Op. cit., p.19.

${ }^{33}$ ID., IB., p. 7.

${ }^{34}$ Mattioli Ross, C. Vivendo volando... Op. cit., p.40.
} 
turista inglês não se considerava rico, mas as 500 libras semanais que retirava do salão, propriedade da família e controlado, assim como o resto dos investimentos familiares, pelo pai, permitiam que Steve morasse sozinho e contasse com a possibilidade de escolher onde passar suas férias anuais. Residindo numa cidadezinha a uns cem quilômetros de Londres, Steve optou por Fortaleza, orientado por um amigo que, nos dois últimos anos, tinha passado meses "maravilhosos" no Nordeste:

To tell the truth, I came here because my friend told me about the girls, how friendly they were, how easy it was to have sex with them... and about the weather.

Steve veio ao Brasil, escolhendo, pela segunda vez nos últimos anos, férias "diferentes" daquelas "socializing" que costumava passar com a família - a irmã, o cunhado $e$ os pais, numa casa, na Catalunha, na qual os pais passam a metade do ano. Na experiência anterior de férias "diferentes" tinha estado em Pattaya, numa viagem considerada fantástica, que marcou suas lembranças. Em relatos orientados por minhas perguntas, ao longo de uma convivência de vários dias nos circuitos turísticos de Fortaleza $^{35}$, Steve contou-me sobre suas experiências sexuais na Inglaterra, na Espanha e na Tailândia, refletindo, à luz delas, sobre os contatos sexuais mantidos em Fortaleza.

Douglas, um advogado estadounidense de 32 anos, solteiro, chegou pela primeira vez ao Brasil em janeiro de 2002, acompanhando um amigo da mesma profissão e nacionalidade, antigo companheiro de universidade. Ambos estudaram em Boston e hoje moram em diferentes cidades dos EEUU. Douglas trabalha de maneira autônoma e ganha aproximadamente U\$50.000 ao ano. O amigo, empregado do Estado, recebe quase o dobro do salário. Douglas escolheu viajar ao Brasil considerando

${ }^{35}$ As entrevistas com Steve e Douglas foram realizadas no marco da pesquisa já mencionada (ver nota inicial), no verão de 2000 e de 2002, respectivamente. 
Exotismo e autenticidade

o país como lugar ideal para minimizar o sofrimento do colega que teria se separado da mulher após ter sabido que ela estava mantendo relações sexuais com uma diversidade de homens. A certeza de que Fortaleza era o destino ideal foi sendo construída após ter visto fotografias do Nordeste no restaurante de um cliente brasileiro - "beaches, jungle and... stunningly beautiful women". Numa pousada não muito distante de Fortaleza, em meio a xícaras de café, e caminhado na beira da praia, Douglas contoume a história de sua viagem, após saber que estava fazendo uma pesquisa sobre turismo internacional $e$ a incidência que ele tem nas escolhas sexuais e amorosas dos locais. O relato centrou-se na percepção da sexualidade das brasileiras.

\section{Convergências}

Essas narrativas diversificadas apresentam uma série de pontos em comum. Não se trata apenas das características dos narradores, que são nativos dos países do Norte, solteiros, de classe média, heterossexuais e brancos - embora seja necessário observar que a cor é um aspecto implícito evidente apenas mediante o contraste com a cor das nativas que, essa sim, é marcada. Refiro-me às convergências nas histórias que são contadas a partir de uma ótica considerada masculina $e$, concedendo maior ou menor peso à solidão, estão centradas em experiências sexuais.

Os narradores, em férias, ou procurando momentos de lazer durante viagens de negócios, consideram-se à maneira de viajantes. Essa qualidade não é necessariamente traçada estabelecendo distinções entre "viagem" e "turismo". Nos termos de Michel, para quem viajar é "praticar o turismo", fazer todos os circuitos do prazer anunciados pelas agências de viagem, "tudo é turístico". ${ }^{36}$ Portanto, ele reflete, viajar no mundo contemporâneo procurando lugares não turísticos seria uma contradição, algo

${ }^{36}$ HouellebecQ, M. Plateforme. Op. cit., p.55 
paradoxal. ${ }^{37} \mathrm{~A}$ qualidade de viajante, ou turista singular $^{38}$, é delineada mediante uma série de diferenciações entre os protagonistas e os (outros) turistas que eles consideram "convencionais".

Trata-se do estilo de viajar, a sós, ou com um amigo, recusando o deslocamento em grupos e/ou pacotes ou, quando se viaja em grupo, distinguindo-se dos outros integrantes. Essa diferenciação pode ser estabelecida através da procura de sexo, ou, quando se trata de distinguir-se de outros turistas sexuais, direcionando essa busca para espaços selecionados, isto é, não invadidos por outros turistas - após ficarem uma semana em Fortaleza, num flat inundado de italianos e garotas "de programa", Douglas e seu amigo decidiram escapar, procurando meninas numa vilinha de pescadores, no litoral do Ceará. Trata-se da procura de alojamentos que possibilitem um contato "real" com os nativos/as - Steve, que chegou a Fortaleza sem referências de hotel, "fugiu" do estabelecimento de 4 estrelas, inteiramente impessoal, ao qual foi conduzido por um taxista, procurando um lugar pequeno, que possibilitasse sua proximidade com "as pessoas". Trata-se, também, da deliberada exposição a situações percebidas como aventuras, à procura de "novidades".

Novidade é, aliás, um termo que, recorrente nos relatos, tende a aludir a diversos tipos de aventura. Pode tratar-se da arriscada experiência de visitar o casebre de uma prostituta num bairro pobre de Ocho Rios, na Jamaica ${ }^{39}$, das emoções quase épicas oferecidas pela travessia em um país oriental ainda em guerra $^{40}$, de uma longuíssima viagem em transporte público rumo à periferia, em Fortaleza, com uma garota à qual se acaba de encontrar, sem ter idéia do destino final e sem condição nenhuma

\footnotetext{
${ }^{37}$ ID., IB., p320.

${ }^{38}$ A idéia de que o "viajante" contemporâneo é um tipo "especial" de turista é recorrente nos textos - ver ID., IB., p.178.

${ }^{39}$ Mattioli Ross, C. Vivendo volando... Op. cit., p.21.

${ }^{40}$ ID., IB. p.28.
} 
Exotismo e autenticidade

de comunicar-se devido ao desconhecimento da língua ${ }^{41}$; da intensa excitação fugindo dos touros em Pamplona ${ }^{42}$, de uma noite de carnaval passada numa prisão no Rio. ${ }^{43}$

Essa busca de aventuras - e das sensações por elas proporcionadas -, é um elemento importante através do qual vários dos narradores aqui contemplados se distinguem dos turistas "convencionais". Mas, o elemento central no distanciamento por todos procurado é a busca de autenticidade em lugares exóticos. Nesses relatos, essa busca adquire uma pluralidade de dimensões. Alguns desses viajantes à procura de sexo procuram, mediante diversas estratégias, descobrir aspectos autênticos dos lugares visitados. A autenticidade pode ser buscada em paisagens, praias, cidades, bairros e/ou no contato com os nativos/as. Mas, não se trata apenas de procurar o verdadeiro "externamente". Em todos os casos, a busca desses turistas é, também, "interna": procuram sensações "autênticas" supostamente suscitadas pela autenticidade daquilo com o qual entram em contato. $\mathrm{O}$ ápice dessas sensações é alcançado através das experiências sexuais. A autenticidade local aparece como corporificada, sobretudo, em "nativas" que, versões palpáveis $(e$ consumíveis) do exotismo, tornam-se a via privilegiada de acesso

${ }^{41}$ Essa foi, precisamente, uma das experiências marcantes na viagem de Steve a Fortaleza. Logo após ter encontrado uma garota na praia, ela o conduziu até uma esquina, onde ficou parada. Ele achou que estavam esperando para atravessar a rua. Mas, descobriu depois que estavam esperando um ônibus. Entrou no veiculo sem ter noção do lugar para o qual estavam se dirigindo. Com certa apreensão, percebeu que o ônibus se afastava muito, em direção aos "outskirts" da cidade. Finalmente desceram. Caminharam um pouco e, finalmente, pararam frente a uma casinha. Ele não tinha a menor idéia do que aconteceria nessa casa. Estava apreensivo, mas, também, excitado. Para sua surpresa, quando entraram, havia uma festa de aniversário, de uma garota de 15/16 anos. Estava a família inteira, havia um bolo de aniversário. E o mais fantástico dessa experiência, para ele, foi ter passado o dia inteiro "not being able to communicate: - not one word".

${ }^{42}$ Mattioli Ross, C. Vivendo volando... Op. cit., p.54.

${ }^{43}$ ID., IB., p. 78. 
à alteridade. E o contato com a feminilidade e sexualidade "natural" dessas mulheres possibilita o acesso a um prazer sexual que adquire o estatuto da experiência mais verdadeira.

\section{Exotismo}

(z)[Do gr. exotikós, pelo lat. exoticu.]

1. Que não é indígena; estrangeiro. [Opõe-se a autóctone (1 e 2).] 2. Esquisito, excêntrico, esdrúxulo, extravagante: 3. Fig. Fam. Malfeito; desajeitado.

A idéia de exotismo faz parte do universo êmico desses viajantes à procura de sexo. Nos termos de Douglas, as "exotic vacations" integram o leque de aspectos do consumo ao qual todo/a estaudonidense aspira. ${ }^{44}$ Nessas histórias, essa noção refere-se à diferença $e$ está intimamente ligada ao erotismo - e vale assinalar que essa vinculação tem uma longa história nos relatos de viagem "ocidentais", nos quais as viagens aos países do Sul são consideradas uma fonte de liberdade erótica. ${ }^{45}$ Nas palavras de Douglas, "é necessário admitir que pessoas de diferentes nacionalidades se atraem, são exóticas umas às outras". Essa atração pode adquirir conotações de verdadeira fascinação. ${ }^{46}$

Stephen Foster assinala que a idéia de exotismo é um elemento simbólico-interpretativo que, entre outras coisas, possibilita aos membros de um grupo social compreender outro grupo social percebido como diferente. No entanto, especificar as dimensões semânticas dessa idéia não seria suficiente: seria necessário, também, especificar suas implicações políticas. ${ }^{47}$

${ }^{44}$ Esses itens incluem "a fancy house, a good car, exotic vacations..."

${ }^{45}$ EDWARDS, Justin D. Exotic Jouneys. Exploring the Erotics of U.S. Travel Literature, 1840-1930. University Press of New England, 2001, pp.2-3.

${ }^{46}$ Mattioli Ross, C. Vivendo volando... Op. cit., p.99.

${ }^{47}$ FOSTER, Stephen William: The exotic as symbolic system Dialectical Antrhopology, September 1982, vol 7, n¹, p.22 
Exotismo e autenticidade

Kamala Kempadoo observa que levar em conta a dimensão política possibilita compreender como o Outro racial, étnico ou cultural é dotado de aspectos românticos, e, simultaneamente, perceber a opressão e exploração que têm lugar no processo de tornar os outros Exóticos. ${ }^{48}$

Nesse sentido, é importante observar que no conjunto dos relatos aqui contemplados a idéia de exotismo é construída através de procedimentos nos quais a alteridade é delineada mediante distinções inseridas em nítidas relações de desigualdade - no sentido de distribuições diferenciadas de poder.

Nas histórias, o exotismo pode referir-se a algo primitivo, ultrapassado, em vias de extinção. Escolhendo circuitos turísticos, Michel chega a cogitar fazer uma viagem a Cuba, seduzido pela idéia de tratar-se de um dos últimos países comunistas, algo em vias de desaparição, uma espécie de "exotismo político". ${ }^{49} \mathrm{E}$ se essa alusão ao exotismo pode parecer ambígua, a valorização negativa da alteridade é evidente nos diversos procedimentos nos quais os mundos dos "nativos" são considerados em termos comparativos e tendo como referência os lugares de origem dos viajantes. ${ }^{50}$

Nesses procedimentos, os diferentes aspectos dos lugares visitados são inferiorizados: o funcionamento das instituições, percebido como corrupto ${ }^{51}$, as habitações "sórdidas" 52 , as cidades, nas quais a miséria adquire dimensões que nunca teriam existido na Europa ${ }^{53}$, caracterizadas por esgotos a céu aberto, por fedor..$^{54}$

\footnotetext{
${ }^{48}$ KemPADOO, Kamala. Gender, race and sex: exoticism in the Caribbean. Paper presented to the International Symposium $O$ desafio da diferença: articulando gênero, raça e classe, Salvador, Brazil, 2000, p.2.

${ }^{49}$ HouellebecQ, M. Plateforme. Op. cit., p.35.

${ }^{50}$ Mattioli Ross, C. Vivendo volando... Op. cit., p.15.

${ }^{51}$ As primeiras referências de Mattioli Ross ao Brasil são histórias que fazem alusão à facilidade de obter financiamentos, seria apenas necessário dar alguma propina e levar máquinas velhas e fabricar qualquer coisa. ID, IB., p.75

52 ID, IB., p.21.

${ }^{53}$ ID, IB., p.27.
} 
Nesses aspectos pode incluir-se o clima - Michel percebe o calor de Bancoc como "seboso" e reflete "é sempre surpreendente, depois de uma longa viagem ao exterior, não se encontrar coberto de uma fina película de resíduos industriais". ${ }^{55}$ Os habitantes desses lugares são apreciados mediante procedimentos análogos àqueles através dos quais são consideradas cidades e paisagens: os hábitos dos "outros" são integrados nesse mapeamento valorativo do exotismo. ${ }^{56}$

Gênero e raça atravessam a construção da alteridade presente nos textos. Nos relatos, a masculinidade nativa tende a ser inferiorizada, particularmente nos graus de encontros mais extremos com a alteridade. ${ }^{57}$ Essa valorização é relativizada quando se traça algum grau de proximidade entre nacionalidades. Nesses casos, o diálogo entre masculinidades, superando as diferenças atribuídas às origens nacionais, põe em evidência a particular inferiorização das mulheres nativas. Referindo-se ao comentário de um taxista mexicano que o aguarda na saída de um prostíbulo em Acapulco, o italiano Mattioli Ross oferece um exemplo desse procedimento:

O tom dele era mais simpático, de uma conivência masculina para além de qualquer preconceito nacionalista. Tinha apenas fodido uma conterrânea dele, mas

\footnotetext{
${ }^{54}$ ID, IB., p.68.

${ }^{55}$ HouellebeCQ, M. Plateforme. Op. cit., p.40.

${ }^{56}$ Nesse sentido é sugestiva a passagem na qual Michel descreve hábitos dos chineses: "Uma mesa de chineses de Hong Kong, reconhecíveis pela sua sujeira, difícil de suportar para um Ocidental... os Chieneses comem com voracidade, riem muito forte com a boca aberta, projetando em volta deles parte da comida, cospem no chão, molham seus dedos - agem em tudo absolutamente como os porcos". ID., IB., p.111.

${ }^{57}$ Referindo-se a Kinmug, Mattioli Ross comenta: "os homens são ainda um pouco selvagens com os estrangeiros". MATTIOLI Ross, C. Vivendo volando... Op. cit., p.68.
} 
Exotismo e autenticidade

evidentemente bastava não ser Americano, do Norte, $e$ depois, cada um [de nós] fazia sua parte. ${ }^{58}$

O marco de relações desiguais nas quais são acionadas essas conceitualizações torna-se evidente prestando atenção à maneira como o exotismo é corporificado por essas "nativas". As marcas da alteridade estão presentes no corpo dessas mulheres expressam-se, por exemplo, nos "olhos negros, com zigomas altos", da prostituta mexicana, que "complementam com um toque indígena, à noite" ${ }^{59}$ Essa percepção da diferença não está isenta de um certo grau de estetização. Descrevendo prostitutas do Vietnã, Mattioli Ross comenta: “...era fácil encontrar nelas aquela doçura nos traços... com os lábios plenos e nos olhos amendoados..." ${ }^{60}$ Retratando uma beleza carioca, esse narrador sublinha seus aspectos distintivos

...não conseguia compreender como podia ter os lábios tão mórbidos, mas devia ser qualquer coisa de índio, como no corte dos olhos, ou de africano... Enfim, uma dessas notáveis combinações que se encontram no Brasil, mesmo se a primeira impressão que se tem é de que seja mais uma nórdica: alta, cabelos claros... e esses lábios excepcionais.

Mas, se a "diferença" é apresentada como um fator de atração, ela também é capaz de repelir, quando certas características corpóreas, tais como a cor, são percebidas como expressão extrema da alteridade. Referindo-se à sua primeira "puttana", com a qual experimentou certas dificuldades sexuais, esse viajante afirma,

Queria provar aquela experiência... Eram todas negras $e$ aquilo tornava a coisa ainda mais misteriosa... Decidi-me

\footnotetext{
${ }^{58}$ ID., IB., p15.

${ }^{59}$ ID., IB., p.11.

${ }^{60}$ ID., IB., p. 70.
} 
por um mulherão sorridente que me parecia reunir dois requisitos: era, sem dúvida nenhuma, negra, e muito, porém tinha um aspecto que dava segurança... Ela tirou também as calcinhas, que me haviam parecido branquíssimas, pelo contraste com a pele, e embaixo era tudo negro... Em nós, certas partes se distinguem melhor: ali, ao contrário, com a luz tênue do abajour, que deveria ter criado uma atmosfera, era tudo escuro. Tomou-me a mão... e a conduziu ao meio das coxas... O pelo crespo aumentou minha crise... Deitou-se sobre o leito para ser mais sugestiva... e passou as duas mãos sobre aquilo que devia ser meu objetivo... A fenda rosada que quase resplandeceu no meio a todo aquele negro aumentou mais ainda minha crise... ${ }^{61}$

O consumo da diferença racializada corporificada por essas mulheres é viabilizada pelo posicionamento desigual das nacionalidades em jogo. Nesse contexto, as "nativas" são objetificadas de maneira particular, num procedimento que é sintetizado nas analogias realizadas entre elas e os órgãos sexuais femininos. ${ }^{62}$ Referindo-se aos turistas presentes num dos bares de Patong Beach (Tailândia), Michel afirma: "Resumindo, o mundo rico ou semi-rico estava lá, respondendo ao apelo imutável e doce da... [vagina] asiática". ${ }^{63}$

Nos termos de um personagem que interage com Michel num bar de Pukhet (Tailândia), um professor francês, já aposentado:

\footnotetext{
${ }^{61}$ Mattioli Ross, C. Vivendo volando... Op. cit., pp.21-22.

${ }^{62}$ É importante assinalar que as interpenetrações entre diferença e desigualdade presentes nessas conceitualizações de exotismo não se restringem, nos relatos, às relações protagonizadas por homens do Primeiro Mundo e mulheres pobres. As mulheres dos países ricos são percebidas como estabelecendo relações análogas. Mattioli Ross, C. Vivendo volando... Op. cit., p.59; HouellebeCQ, M. Plateforme. Op. cit., p.243.

${ }^{63}$ HouellebeCQ, M. Plateforme. Op. cit., p.115.
} 
Exotismo e autenticidade

Sou racista... virei racista... Um dos primeiros efeitos da viagem, adiciona, consiste em reforçar ou criar os preconceitos raciais, porque, como imaginar os outros antes de conhecê-los? Aos cinqüenta anos de idade, enfarado do ensino, das matemáticas e de todas as coisas, decidi descobrir o mundo. Acabava de divorciar-me pela terceira vez; no plano sexual, não esperava nada em particular. Minha primeira viagem foi para a Tailândia, em seguida, parti para Madagascar. Depois disso, nunca mais [fiz sexo] com uma Branca... Acredita em mim, a boa ... [vagina] doce, dócil, macia e musculosa, jamais a encontrará numa Branca, tudo isso desapareceu completamente... O racismo... parece caracterizar-se por uma antipatia aguda, uma sensação de competição violenta entre machos de raças diferentes ${ }^{64}$, mas tem como corolário o aumento do desejo pelas mulheres da outra raça. O verdadeiro jogo da luta racial... não é econômico, nem cultural, é a competição pela vagina das mulheres jovens... Estive no Senegal, em Quênia, na Tanzânia, na Costa do Marfim. As meninas são menos expertas que as Thais, é verdade, são menos doces, mas elas têm muitas curvas e uma... [vagina] perfumada. ${ }^{65}$

As análises sobre a dinâmica do turismo sexual internacional apontam para o fato de os bolsos dos turistas sexuais Ocidentais conterem suficiente poder para converter os outros em Outros, meros atores num palco pornográfico, como uma expressão do enorme desequilíbrio econômico, social e político entre nações pobres e ricas. ${ }^{66}$ A percepção desse desequilíbrio faz parte do universo êmico dos relatos. Michel explicita:

\footnotetext{
${ }^{64} \mathrm{~A}$ idéia de que, no marco do turismo sexual internacional, os nativos são os verdadeiros perdedores se reitera nos diversos relatos. Douglas afirma que fica com pena dos homens locais (cearenses) que são, ele acha, os grandes perdedores da história.

${ }^{65}$ HouellebecQ, M. Plateforme. Op. cit., pp.119-122.

${ }^{66}$ O'CONNELl DAVIDSON, Julia e SANCHEZ TAYLOR, Jacqueline. Fantasy Islands: Exploring the demand for Sex Tourism. In: Kempadoo, Kamala. Sun, sex, and
} 
De um lado tu tens várias centenas de milhares de Ocidentais que têm tudo o que querem, mas que não conseguem alcançar a satisfação sexual, procuram, procuram sem parar, mas não encontram nada, são infelizes. De outro lado, tens vários milhares de indivíduos que não tem nada, que caem de fome, que morrem jovens, que vivem em condições insalubres, que não tem nada a vender para além de seus corpos, e sua sexualidade intacta. É simples, verdadeiramente simples a ser compreendido: é uma situação de intercâmbio ideal. ${ }^{67}$

Nas narrativas, a desigualdade que perpassa esses "intercâmbios" torna-se evidente no marco do exercício da sexualidade. Mas, essas "trocas," longe de serem apresentadas apenas como sexo de fácil acesso, são valorizadas em tanto possibilidade de contato "real" com o outro.

\section{Autenticidade}

Verbete: autêntico [Do gr. authentikós, pelo lat. authenticu.]

Adj.

1. Que é do autor a quem se atribui. 2. A que se pode dar fé; fidedigno:

3. Que faz fé:

4. Legalizado, autenticado.

5. Verdadeiro, real:

6. Genuíno legítimo, lídimo:

Nesses relatos, as imagens adquirem um papel importante na avaliação da autenticidade dos lugares visitados e/ou dos "outros" com os quais se entra em contato. A construção dessas imagens é resultado de um processo complexo e amplamente

gold. Tourism and Sex Work in the Caribbean. Oxford, Rowman \& Littlefield, 1999, p.53.

${ }^{67}$ HouellebeCQ, M. Plateforme. Op. cit., p.252. 
Exotismo e autenticidade

diversificado. A literatura - os romances de Salgari -, conduziu Mattioli Ross às Antilhas ${ }^{68}$, as imagens televisivas o levaram ao templo de Angkor, em Camboja; as primeiras músicas que chegaram do Brasil e o filme Orfeu Negro o instigaram a subir à favela, no $\mathrm{Rio}^{69}$, os relatos de outros viajantes e as fotografias por eles carregadas conduziram Steve e Douglas a Fortaleza. As imagens produzidas por brochuras $e$ folhetos de viagem inspiraram Michel, provocando-lhe, ainda, um imenso prazer, por sua maneira de reduzir o mundo a uma seqüência ilimitada de possíveis confortos e tarifas. ${ }^{70}$

Um dos procedimentos para a criação da sensação de autenticidade, presente nessas narrativas, é uma constante comparação entre as imagens e o lugar, na qual este último deve assemelhar-se às primeiras; entre o lugar e outros lugares; entre as imagens dos "nativos" $e$ os habitantes desses lugares, particularmente as mulheres - Douglas me explica que as mulheres de Fortaleza são diferentes do que ele esperava, menos bonitas, muito interessadas em dinheiro. Em Beberibe são mais parecidas com o que ele imaginou, "beautiful and sweet, real Brazilian girls".

No conjunto dos textos, a autenticidade adquire relevância, sobretudo, em termos da possibilidade de estimular sensações qualitativamente superiores, na medida em que são percebidas como autênticas. As cidades orientais autênticas são aquelas que provocam a sensação de estar em Oriente - e não em qualquer centro internacional. ${ }^{71}$ Nesses termos, o fato de ser uma imitação de outros lugares não apaga, necessariamente, a autenticidade.

${ }^{68}$ Mattioli Ross, C. Vivendo volando... Op. cit., p.19.

${ }^{69}$ ID., IB., p.79.

${ }^{70} \mathrm{O}$ narrador atribui ao folheto peso na sua decisão pela Tailândia: "Um circuito organizado, com um toque de aventura, que os levará dos bambus do rio Kwai à ilha de Hoh Samui, para finalizar em Koh Phi Phi, ao longo de Phuket, após uma travessia magnífica do istmo de Kra. Uma viagem 'cool' nos trópicos." HouelleBeCQ, M. Plateforme. Op. cit., p.22, 35

${ }^{71}$ Mattioli Ross, C. Vivendo volando... Op. cit., p.68. 
Nesse sentido, os comentários de Mattioli Ross sobre Las Vegas, cidade que replica monumentos presentes em outros lugares, são significativos:

Seria fácil conformar-se com uma definição assim se fosse uma má imitação de qualquer outro lugar, mas como cidade, ela tem raça. Não é possível compará-la a nenhuma outra. $^{72}$

A sensação de autenticidade enquanto viajante pode estar ligada à emoção produzida pelo fato de ser o único estrangeiro no meio dos nativos ${ }^{73}$, numa praia, num transporte público $e$, inclusive num bordel. Nuns e outros relatos, porém, o ponto mais intenso dessas sensações é alcançado através das experiências sexuais, basicamente, com as nativas. $\mathrm{Na}$ construção dessa sensação confluem visões correntes na cultura ocidental sobre a relação sexual enquanto condensação da idéia de relação social e imagens sobre as sexualidades do Terceiro Mundo delineadas em termos comparativos, isto é, contrastando-as com os estilos de sexualidade atribuídos aos europeus, sobretudo, às européias. Mas, o "verdadeiro" prazer obtido nesses contatos com os habitantes dos países do Sul está intimamente ligado à idéia de um exercício permanente de poder.

O jogo de forças presentes nos encontros sexuais é particularmente evidente nos relacionamentos com as mulheres que compartilham a nacionalidade e classe social dos viajantes. A "igualdade" com as conterrâneas - consideradas "bitchy", por Douglas, que se refere nesses termos às mulheres estadounidenses, frias e exigentes; "arrogantes", por Steve, que assim percebe as inglesas - redunda em relacionamentos sexuais perpassados por uma negociação desgastante e pouco prazerosa. Esse jogo de forças, porém, não deixa de estar presente nas

${ }^{72}$ ID., IB., p. 169
${ }^{73}$ ID., IB., p. 152 
Exotismo e autenticidade

relações com as mulheres do Terceiro Mundo, inclusive com as prostitutas.

Nos relatos, esses encontros são sempre apresentados como perpassados por uma dinâmica de poder. No entanto, as narrativas mostram diferentes maneiras de perceber essa dinâmica. Alguns narradores parecem ignorar a desigualdade inerente aos relacionamentos sexuais que estabelecem com as "nativas" do Terceiro Mundo. Nesses casos, esses encontros evocam a idéia de aventura, de desafio, de território a ser subjugado e o sucesso nesse empreendimento se expressa na obtenção de certa subordinação das "amantes" ${ }^{74}$ Vale reiterar que, nos relatos, isso é possível apenas quando se trata de amantes "exóticas" - as mulheres do Primeiro Mundo aparecem como inteiramente distantes dessa possibilidade. E utilizo aqui a expressão "certa" subordinação propositalmente. A subordinação absoluta não é necessariamente considerada prazerosa. As (insossas) experiências com quase crianças são, nesse, sentido, exemplos do (dis)sabor que resulta do controle absoluto. ${ }^{75}$

Mas, não se trata apenas da obtenção desse relativo controle. Ás vezes é também necessário que ele seja exercido em relação a mulheres inseridas no mundo da prostituição cujas atitudes as distanciem desse mundo - refiro-me à recusa do pagamento, ao estabelecimento de laços afetuosos com o protagonista $^{76} \mathrm{e} / \mathrm{ou}$ ao fato de as prostitutas expressarem prazer nas relações sexuais. Esta afirmação pode soar paradoxal levando em conta que se trata de viajantes à procura de sexo. No entanto, essas preferências, tratadas como "ficções de mutualidade", são registradas uma e outra vez, tanto em trabalhos sobre turismo

\footnotetext{
${ }^{74}$ Mattioli Ross, C. Vivendo volando... Op. cit., p.12

${ }^{75}$ ID., IB., p.30.

${ }^{76}$ Mattioli Ross, C. Vivendo volando... Op. cit., p.16, 106.
} 
sexual $^{77}$ como em análises das relações estabelecidas por prostitutas com seus conterrâneos. ${ }^{78}$

Alguns relatos partem, porém, da constatação das relações de desigualdade permeando esses encontros. Nesses casos, a relação poder/prazer não é situada na interação entre os agentes envolvidos no encontro sexual de maneira linear. Trata-se, sobretudo, do prazer vinculado a certas características atribuídas às feminilidades do Terceiro Mundo - submissão, doçura, generosidade - que aparecem como efeitos dessas relações desiguais. Nessa percepção, os "poderes" das prostitutas, capazes de exercer um certo controle sobre os viajantes à procura de sexo mediante o gozo que proporcionam, são altamente apreciados. ${ }^{79}$ Mas, nuns e outros relatos, e esse é o ponto que quero destacar, a desigualdade é inerente a esses contatos que são apresentados como "verdadeira" conexão social.

Considerados em contraposição à solidão intolerável, ao desespero que resulta do afastamento de todo contato humano, caloroso e vivo - nos termos de Michel, o estado inerente aos europeus -, os contatos sexuais com as prostitutas do Terceiro Mundo adquirem o estatuto de relação social "real". Essas relações, porém, apresentam características específicas. Michel aprecia as práticas sexuais singulares das prostitutas tailandesas. ${ }^{80}$ No entanto, o prazer por elas proporcionado é vinculado,

77 O'Connell Davidson, Julia. Prostitution, power and freedom. Ann Arbor, The University of Michigan Press, 1998, pp.158-159.

${ }^{78}$ PASINI, Elisiane. Homens da vida: um estudo sobre sexualidade(s) masculina(s) em um contexto de prostituição feminina. Texto apresentado no Seminário de Tese do Doutorado em Ciências Sociais - Área Família e Gênero, maio 2002.

${ }^{79}$ HouellebeCQ, M. Plateforme. Op. cit., p.53.

${ }^{80}$ Michel valoriza particularmente o espantoso domínio das prostitutas Thai da musculatura vaginal. Essa apreciação é compartilhada por outros personagens do romance de Houellebecq. Um turista sexual que conversa com Michel afirma com seriedade: "falam das brasileiras, ou das meninas de Cuba. Tenho viajado muito, para o meu prazer, e não tenho dúvidas: para mim, as tailandesas são as melhores amantes do mundo". HouelleBECQ, M. Plateforme. Op. cit., p.81. 
Exotismo e autenticidade

sobretudo, à disposição especial para "dar prazer" atribuída a essas mulheres, percebida como traço inerente a suas feminilidades e considerada como inexistente entre as européias, inclusive entre as prostitutas. ${ }^{81}$ As européias, o narrador reflete, não experimentam prazer nem desejam dar prazer, particularmente as francesas. Elas não têm interesse no sexo, apenas na sedução e são inteiramente incapazes na cama: carecem de qualquer naturalidade, de qualquer "inocência sexual". 82

$\mathrm{Na}$ opinião de Michel, os Ocidentais não fazem mais sexo, algo que ele considera problemático, uma "falta" que está vinculada a um grau extremo de narcisismo, de individualidade. Frios, racionais, extremamente conscientes de sua existência individual e de seus direitos, obcecados pela saúde e pela higiene, evitando todo tipo de dependência, os europeus não seriam (mais) capazes de obsessão sexual nem de exaltação sentimental, uma vez que ambas exigem esquecer-se parcialmente de si. Seria impossível fazer o amor sem um certo abandono, sem aceitar pelo menos de maneira temporária um certo estado de dependência e de fragilidade..$^{83} \mathrm{O}$ sado-masoquismo organizado, um movimento crescente na Europa, um universo puramente cerebral, com regras precisas, no qual cada um dos participantes permanece fechado

${ }^{81}$ Steve, pondo em perspectiva garotas (de programa) brasileiras, tailandesas e mulheres inglesas, manifesta opiniões análogas: "They seem to want to please men. Anything".

${ }^{82}$ HouellebeCQ, M. Plateforme. Op. cit., p.216.

${ }^{83}$ Discutindo o sado-masoquismo com outro personagem, o narrador discorda da idéia de que o sofrimento $e$ a crueldade, a dominação $e$ a servidão constituam a natureza íntima da sexualidade. Considera seriamente os argumentos da namorada francesa quando ela afirma que essas práticas, nas quais todo mundo leva luvas, usa utensílios, nas quais jamais há contato físico, as peles não se tocam, não há beijos, nem carícias, são exatamente o contrário da sexualidade. Mas, pondera Michel, há diversas sexualidades. Os Sado-Masoquistas vêem em suas práticas a apoteose da sexualidade. Por outro lado, as práticas que exigem contato, a penetração, por exemplo, exigem uma capacidade de abandono cada vez mais distante das européias. HouELLEBECQ, M. Plateforme. Op. cit., p.251. 
na sua pele, plenamente livre em suas sensações de ser único, representaria esse ethos. ${ }^{84}$ Segundo Michel, o "sexo real, animal... natural", encontra-se hoje nos países do Terceiro Mundo. ${ }^{85}$ E ele se expressa no desejo de oferecer o corpo como um objeto agradável.

Observando os argumentos apresentados num debate que pouco tem a ver com as questões aqui tratadas, Marilyn Strathern afirma que, para os euro-americanos, o relacionamento sexual significa a importância atribuída aos relacionamentos em geral isto é, o intercurso sexual é percebido como inerentemente relacional. ${ }^{86}$ Essa idéia parece perpassar as formulações dos relatos aqui contemplados - ela está presente, aliás, nos argumentos centrais mediante os quais se justificam as viagens à procura de sexo aos países do Terceiro Mundo.

Nesse jogo de contrastes Norte/Sul, entre feminilidades $e$ entre sexualidades, esses contatos sexuais assumem o estatuto de "verdadeiras" possibilidades de conexão social com a alteridade $e$ de fonte de sensações "autênticas". Nos relatos, o sexo alocado ao Terceiro Mundo aparece como "real" na medida em que é "natural" - e essa idéia de natural alude tanto à idéia de relação como ao estabelecimento de relações marcadas pelo procedimento de tornar o outro exótico, pela objetificação e a desigualdade. Essas são as relações que viabilizam o acesso a um prazer cujo valor reside na "autenticidade" das sensações $e$, portanto, da satisfação que supostamente provoca.

\footnotetext{
${ }^{84}$ Valérie, namorada francesa de Michel, apresentaria características inteiramente inusuais nas européias: submissa, doce, cálida, nada exigente, gentil, intensamente sexuada, generosa. $\mathrm{E}$, diferentemente das mulheres do Terceiro Mundo seria, também, inteligente. ID., IB., pp.51-57.

${ }^{85}$ ID., IB., p.255.

${ }^{86}$ StRATHERn, Marilyn. Necessidade de pais, necessidade de mães. Revista de Estudos Feministas, vol 3, n² 2, 1995, pp.313-314.
} 
Exotismo e autenticidade

\section{Concluindo}

Os relatos aqui analisados mostram, sem dúvida, que o turismo tem a ver com a maneira como os "outros" são imaginados, isto é, aludem ao caráter mediado da experiência turística contemporânea. Ao mesmo tempo, essas narrativas, que embaralham idéias presentes em diversas abordagens sócioantropológicas sobre turismo, oferecem elementos para considerar a distinção entre viagem $e$ turismo ancorada nas discussões sobre autenticidade.

Os narradores representam uma das expressões consideradas mais extremas (e abjetas) do turismo pós-industrial, caracterizado como intrinsecamente não autêntico. No entanto, eles se apresentam traçando relações que resultam paradoxais, levando em conta as tipologias de turistas que traçam distinções entre aqueles voltados para a procura do prazer $e$ os interessados na autenticidade. À maneira do turista imaginado por MacCannell, esses narradores fogem de uma sociedade percebida como alienada e caracterizada pela não-conexão, mas o fazem procurando experiências "reais" que unem prazer e autenticidade.

Considerando o turismo como a forma de viagem no mundo contemporâneo, os argumentos dos protagonistas desses relatos confundem aspectos presentes na clássica distinção entre "viagem" e turismo - "Tudo é turismo", afirma Michel. Ao mesmo tempo, nessas histórias os "viajantes" constituem uma categoria especial de turistas, diferenciada pela busca de aventuras, de relações "verdadeiras" com os nativos e de sensações autênticas. Mas é, sobretudo, a implementação da noção de autenticidade o ponto central nessa embaralhamento. Tornando "reais" os contatos com prostitutas do Terceiro Mundo mediante a operacionalização da noção de intercurso sexual como relação social, e ligando a "autenticidade" às sensações (internas) suscitadas por essas relações, a maneira como os relatos desses narradores justifica as viagens à procura de sexo neutraliza, ao 
Adriana Piscitelli

mesmo tempo, a concepção do turismo (sexual) como marcado pela falta de autenticidade. 